University of South Carolina

Scholar Commons

$10-2005$

\title{
The Relationship Between Leisure-Time Physical Activity and the Metabolic Syndrome: An Examination of NHANES III, 1988-1994
}

\author{
Katrina D. DuBose \\ Cheryl L. Addy \\ Barbara E. Ainsworth \\ Gregory A. Hand \\ J. Larry Durstine \\ Idurstin@mailbox.sc.edu
}

Follow this and additional works at: https://scholarcommons.sc.edu/

sph_physical_activity_public_health_facpub

Part of the Public Health Commons

\section{Publication Info}

Published in Journal of Physical Activity and Health, Volume 2, Issue 4, 2005, pages 470-487.

Dubose, K.D., Addy, C.L. , Ainsworth B.E. , Hand G.A. , Durstine, J.L. (2005). The relationship between leisure-time physical activity \& the metabolic syndrome: An examination of NHANES III, 1988-1994. Journal Physical Activity Health. 2(4), 470-487.

(c) Journal of Physical Activity and Health 2005, Human Kinetics.

This Article is brought to you by the Physical Activity and Public Health at Scholar Commons. It has been accepted for inclusion in Faculty Publications by an authorized administrator of Scholar Commons. For more information, please contact digres@mailbox.sc.edu. 


\title{
The Relationship Between Leisure-Time Physical Activity and the Metabolic Syndrome: An Examination of NHANES III, 1988-1994
}

\author{
Katrina D. DuBose, Cheryl L. Addy, Barbara E. Ainsworth, \\ Gregory A. Hand, and J. Larry Durstine
}

\begin{abstract}
Background: This study was performed to determine the relationship between leisure-time physical activity (LTPA) and the metabolic syndrome (MS) in 16,681 adults (43 $\pm 0.44 \mathrm{y}$ ) enrolled in NHANES III. Methods: LTPA was classified as regularly active ( $\geq 5 \mathrm{~d} /$ wk moderate and/or $\geq 3 \mathrm{~d} /$ wk vigorous), irregularly active (some LTPA), or inactive (no LTPA). The MS was positive with three or more conditions: 1) abdominal obesity, 2) low HDL-C, 3) hypertriglyceridemia, 4) elevated blood pressure, or 5) elevated glucose. Logistic regression examined the relationship between LTPA and the MS, adjusting for age, race, smoking status, and educational attainment stratified by gender. Results: In men only, irregular activity and inactivity was related to an increase in the MS (irregular: $\mathrm{OR}=1.52$ 95\% CI 1.11, 1.23; inactive: $\mathrm{OR}=1.60,95 \%$ CI 1.18, 1.98 ; test for trend $P=0.004$ ). Inactivity increased the odds for abdominal obesity $(P<0.05)$. Conclusions: LTPA levels might influence the development of MS and abdominal obesity.
\end{abstract}

Key Words: syndrome X, exercise, population study, CVD risk factors

The metabolic syndrome is defined as the presence of three or more of the following conditions: 1) abdominal obesity, 2) elevated triglycerides, 3) low high-densitylipoprotein cholesterol (HDL-C), 4) impaired glucose tolerance, and 5) hypertension. ${ }^{1}$ The presence of the metabolic syndrome increases the risk for ischemic heart disease and CVD-related mortality. ${ }^{2}{ }^{3}$ Between 2002 and 2003, the prevalence of the metabolic syndrome among study populations in the US was reported to be between 20 and $27 \% .^{4,5}$

\footnotetext{
DuBose is with the Schiefelbusch Institute for Life Span Studies, Center for Physical Activity \& Weight Management, University of Kansas, Lawrence, KS 66045. Addy is with the Dept of Epidemiology \& Biostatistics, Arnold School of Public Health, University of South Carolina, Columbia, SC 29208. Ainsworth is with the Dept of Exercise \& Nutritional Sciences, San Diego State University, San Diego, CA 92182. Hand and Durstine are with the Dept of Exercise Science, Arnold School of Public Health, University of South Carolina, Columbia, SC 29208.
} 
Physical inactivity has been related to components of the metabolic syndrome that increase the risk for chronic disease.$^{6-8}$ Few studies have identified associations between physical activity and the metabolic syndrome. In a study of 4978 men and 2035 women living in England, Brunner et al. ${ }^{9}$ showed no association between moderate- or vigorous-intensity physical activity and the metabolic syndrome. In contrast, Irwin et al. ${ }^{10}$ and Laaksonen, et al. ${ }^{11}$ showed associations between regular participation in moderate- and vigorous- intensity physical activity and a lower prevalence in the metabolic syndrome; however, these studies were reported in relatively small homogeneous samples.

The studies described above used different definitions for the metabolic syndrome and for classifying physical activity as moderate- and vigorous-intensity which could explain differences in results. Brunner et al. ${ }^{9}$ defined individuals as having the metabolic syndrome when three or more of the following components were in the top sex-specific quintile:1) 2-h glucose (after an oral glucose tolerance test), 2) systolic blood pressure, 3) fasting triglycerides, 4) HDL-C (bottom quintile), and 5) waist-hip ratio. Physical activity was assessed by a questionnaire and physical activity levels were classified as none/mild ( $<1.5 \mathrm{~h} / \mathrm{wk}$ of moderate or vigorous), moderate $(\geq 1.5 \mathrm{~h} / \mathrm{wk}$ of moderate and $<1.5 \mathrm{~h} / \mathrm{wk}$ of vigorous $)$, and vigorous ( $\geq 1.5 \mathrm{~h} /$ wk of vigorous). Laaksonen et al. ${ }^{11}$ defined the metabolic syndrome according to the World Health Organization definition ${ }^{12}$ and the Adult Treatment Panel III (ATP-III). Physical activity was measured using the Kuopio Ischemic Heart Disease 12-month leisure time physical activity (LTPA) questionnaire. Moderate-vigorous-intensity physical activity was defined as activities greater than 4.5 METs and vigorous-intensity physical activity was defined as activities greater than 7.5 METs. In contrast, Iwrin et al. ${ }^{10}$ defined the metabolic syndrome according to ATP-III guidelines. ${ }^{1}$ Physical activity levels were assessed from physical activity records that were kept by participants for two 4-d periods. Moderate-intensity physical activity was defined as activities between 3 to 6 METs and vigorous-intensity physical activity were activities greater than 6 METs. ${ }^{13}$

Carroll et al. ${ }^{14}$ further demonstrated the difficulties of studying associations between physical activity and the metabolic syndrome in a cross-sectional study of 711 adult men. The results showed that the relationship between physical activity and the metabolic syndrome was dependent on the cut-points used to define each component of the metabolic syndrome. When the cut-points were defined by quartiles, moderate-vigorous and vigorous-intensity physical activity were inversely related with the metabolic syndrome; however, when the cut-points were based on clinically established values (i.e., HDL-C $<35 \mathrm{mg} / \mathrm{dL}$, triglyceride $>150 \mathrm{mg} / \mathrm{dL}$, and $\mathrm{BMI} \geq 30 \mathrm{~kg} / \mathrm{m}^{2}$ ), the association between physical activity and the metabolic syndrome no longer existed.

The results from previous studies suggest physical activity positively impacts the metabolic syndrome; however, due to inconsistent definitions of the metabolic syndrome and physical activity measures, the influence physical activity has on the metabolic syndrome is unclear. In addition, few studies have examined the association between physical activity and the metabolic syndrome using definitions for the metabolic syndrome standardized by the ATP-III criteria. Therefore, this study was performed to examine the relationship between LTPA and the metabolic syndrome using ATP-III criteria in a representative adult population from the US. 


\section{Methods}

\section{Study Design}

Data were obtained from the Third National Health and Nutrition Examination Survey (NHANES III), which was conducted by the National Center for Health Statistics, Centers for Disease Control and Prevention, between the years of 1988 to 1994. NHANES III is a cross-sectional study design involving a national multistage probability sample of non-institutionalized US population. ${ }^{15}$ To obtain a representative sample of people living in the US, NHANES III over-sampled youth, older adults, African Americans, and Mexican Americans. The NHANES III survey consisted of interviewer-administered questionnaires conducted in the participants' home by trained staff and followed by standardized medical examinations by physicians and health technicians that were conducted in Mobile Examination Centers. The questionnaires included information about age, ethnicity, gender, physical activity and nutritional habits, and current medical conditions. Medical examinations were performed to evaluate anthropometric, blood pressure, blood assays, and, for a subset of the population, a response to an oral glucose tolerance test.

\section{Study Participants}

The total NHANES III sample consisted of 33,994 individuals between the ages of 2 months and $99 \mathrm{y}$ who participated in the survey portion of the study. Among the 31,311 participants who completed the medical examination in NHANES III, 432 were excluded for being younger than $18 \mathrm{y}, 2767$ were previously diagnosed with coronary heart disease, 2330 did not have glucose measured, of that 1363 did not have the oral glucose tolerance test (only for participants age 40 to $74 \mathrm{y}$ ) and 967 did not have a fasted glucose sample (for participants age 18 to $39 \mathrm{y}$ ), $3892 \mathrm{had}$ incomplete data for the other components of the metabolic syndrome and 2879 had incomplete data for leisure-time physical activity level. After excluding these 14,630 participants, 16,681 were eligible for data analysis. To protect human subjects in research, approval to analyze the NHANES III public dataset was obtained from the University of South Carolina's Institutional Review Board.

\section{Demographic Information}

Demographic information was collected to describe characteristics of the participants enrolled in NHANES III. The variables measured were race/ethnicity, age, and sex. Self-reported educational attainment was also queried and classified as: 1) less than high school (<12 y), 2) completed high school (12 y), 3) some college education or completed college (13 to $16 \mathrm{y}$ ), or 4) education beyond college (>16 y). Smoking status was queried and classified as: 1) current smoker, 2) past smoker (reported smoking in the past, but not currently) or 3) non-smoker (reported never smoking).

\section{Leisure-Time Physical Activity}

The leisure-time physical activity (LTPA) questionnaire was adapted from the 1985 National Health Interviewer Survey which determined baseline estimates for the 
Healthy People 2000 physical activity objectives. LTPA was assessed through a series of questions querying specific activities (e.g., gardening, running, walking, swimming, etc.) performed in the past month and the frequency of each activity per month. Duration of each LTPA bout was not assessed in NHANES III. Therefore, quantification of activity-related energy expenditure as a continuous variable was not possible, and LTPA was defined as a 3 level categorical variable (e.g., inactive, irregularly active, and regularly active) to examine dose-response characteristics of physical activity status. Moderate-intensity physical activity was defined as activities ranging from 3 to $6 \mathrm{MET}$ s in intensity and vigorous-intensity physical activity was defined as activities > 6 METs. The Compendium of Physical Activities was used to classify the intensity of the reported physical activities. ${ }^{16}$ One MET is defined as approximately $1 \mathrm{kcal} \cdot \mathrm{h}^{1} \cdot \mathrm{kg}$ body $\mathrm{wt}^{-1}$. The frequency of LTPA was expressed as days per week and computed by dividing the number of days per month of physical activity participation by 4.3 wk per month. ${ }^{17}$ Participants completing $\geq 5 \mathrm{~d} / \mathrm{wk}$ of moderate-intensity physical activities and/or $\geq 3 \mathrm{~d} /$ wk of vigorous-intensity physical activities were classified as regularly active. Participants who reported some activity, but not $\geq 5 \mathrm{~d} /$ wk of moderate-intensity activity or $\geq 3 \mathrm{~d} /$ wk of vigorousintensity physical activity were classified as irregularly active. Participants who did not report any LTPA in the past month were classified as inactive.

\section{The Metabolic Syndrome}

The ATP-III report ${ }^{1}$ was used to define the presence of the metabolic syndrome. The metabolic syndrome was defined as the presence of three or more of the following components: 1) abdominal obesity (waist circumference $>102 \mathrm{~cm}$ in men and $>88 \mathrm{~cm}$ in women), 2) elevated triglyceride concentration ( $\geq 150 \mathrm{mg} / \mathrm{dL}$ ), 3) low HDL-C concentration ( $<40 \mathrm{mg} / \mathrm{dL}$ in men and $<50 \mathrm{mg} / \mathrm{dL}$ in women), 4) elevated blood pressure (systolic $\geq 130 \mathrm{mmHg}$ or diastolic $\geq 85 \mathrm{mmHg}$ ), or 5) elevated fasting glucose concentration ( $\geq 110 \mathrm{mg} / \mathrm{dL}$ ). The ATP-III report does not stipulate whether both elevated systolic or diastolic blood pressure must be present, so in this study the presence of either elevated systolic or diastolic blood pressure was accepted as elevated blood pressure. Participants currently taking anti-hypertensive medication were classified as having high blood pressure. Participants currently taking hypoglycemic agents were classified as having high glucose levels.

\section{Anthropometric Data}

Body weight was measured in kilograms using a digital scale (Toledo Scale, Toledo, $\mathrm{OH})$. Participants were weighed in their clothing with their shoes off. The average of 2 measurements was used for data analysis. Height was measured to the nearest $0.1 \mathrm{~cm}$ using a stadiometer (Seca, Shorr Production, Olney, MD). A standing height photograph was made and the height was measured from the photograph. Height was measured with the participant's shoes off. The average of 2 measurements was used for data analysis. Body-mass index (BMI) was calculated as weight (kg) divided by height $(\mathrm{m})^{2}$. Based on criteria established by the National Institutes of Health ${ }^{18}$ to classify BMI, participants were grouped into one of the following three categories of BMI: 1) normal $\left(<25 \mathrm{~kg} / \mathrm{m}^{2}\right), 2$ ) overweight (25 to $29.9 \mathrm{~kg} / \mathrm{m}^{2}$ ), or 3) obese $\left(\geq 30 \mathrm{~kg} / \mathrm{m}^{2}\right)$. Waist circumference was measured using a steel tape measure at the 
level of the iliac crest in the horizontal plane underneath the participant's clothing. The tape was placed parallel to the floor and pulled taut around the participant's body, but did not compress the skin. Waist circumference was measured in duplicate to the nearest $0.1 \mathrm{~cm}$ with the average used for data analysis.

\section{Blood Pressure}

Blood pressure measurements were taken following the guidelines developed by Westat, Inc. (Rockville, MD) and outlined in the NHANES III Manual of Operations. ${ }^{15}$ Systolic and diastolic blood pressure measurements were taken 5 min after the subject was sitting quietly. A standard mercury sphygmomanometer (W. A. Baum Co., Inc., Copiague, NY), a blood pressure cuff based on the circumference of the participant's arm (e.g., infant, regular, adult, large, or thigh size), and a stethoscope (Littman Classic, St. Paul, MN) were used to measure blood pressure. The first and fifth Korotkoff sounds designated systolic and diastolic blood pressures, respectively. Three blood pressure readings were taken and the average of the second and third readings was used in data analysis.

\section{Blood Collection and Storage}

Blood samples were collected after a 12-h fast, using standard venipuncture methods by a trained phlebotomist. Blood samples were processed at the study site by centrifuging the samples at $1500 \times g$ for $10 \mathrm{~min}$, placing the serum in pre-labeled vials, storing the samples at $-70{ }^{\circ} \mathrm{C}$, and shipping the samples to the NHANES III designated laboratories for further processing. Blood samples remained stored at $-70{ }^{\circ} \mathrm{C}$ until analyses were conducted.

\section{Glucose Assay}

Glucose concentrations were analyzed at the Department of Child Health, University of Missouri-Columbia, Columbia, MO. Glucose levels were measured enzymatically using a Cobas Mira Chemistry System (Roche Diagnostic Systems, Inc., Montclair, NJ). The coefficient of variation was between 1.6 to $3.7 \%$ for both intra- and inter-assay quality control during the $6 \mathrm{y}$ of data collection.

\section{Blood Lipids}

Triglyceride and HDL-C concentrations were analyzed at the Lipoprotein Analytical Laboratory, Johns Hopkins University, Baltimore, MD. All measurements were determined by standardized methods outlined by the Lipids Research Clinics program. ${ }^{19}$ Triglyceride was measured enzymatically by hydrolysis to form an intermediate product, glycerol, which was oxidized by glycerol oxidase. The coefficient of variation was between 2.45 to $3.02 \%$ for both intra- and inter-assay quality control during the $6 \mathrm{y}$ of data collection. HDL-C concentrations were measured by a heparin-manganese chloride mixture $\left(\mathrm{MnCl}_{2}\right)$ after other lipoproteins were precipitated with a polyanion/divalent cation mixture. The coefficient of variation was between 1.46 to $7.73 \%$ for both intra- and inter-assay quality control during the $6 \mathrm{y}$ of data collection. 


\section{Statistical Analyses}

Means, standard error, and percentages were computed for descriptive data. Prevalence estimates for LTPA were determined for each gender by race, adjusting for age. Prevalence estimates for the metabolic syndrome and its related components by LTPA were determined for each gender by race, adjusting for age. Multiple logistic regression analysis was used to estimate odds ratios (OR) and 95\% confidence intervals (CI) of the metabolic syndrome as a function of the 3 levels of physical activity participation adjusting for age, race, smoking status, and educational attainment stratified by gender. Multiple logistic regression analyses were also conducted to estimate OR and $95 \%$ CI of the components of the metabolic syndrome as a function of the 3 levels of physical activity participation, adjusting for age, race, smoking status, and educational attainment stratified by gender. The data were analyzed using SAS-callable SUDAAN (version 8.0, Research Triangle, Cary, NC). All hypotheses were tested at the 0.05 alpha level.

\section{Results}

Means, standard error, and percentage of descriptive characteristics of the study participants are shown in Table 1. On average, the participants were classified as overweight and had normal levels of HDL-C, triglycerides, fasting glucose, and blood pressure. The majority of subjects were non-Hispanic Caucasians and were either current or past smokers. Among those who were told that they had hypertension or elevated cholesterol levels, the majority were taking medication to lower their blood pressure and less than $15 \%$ of the participants were taking medication to lower their cholesterol levels.

Table 2 shows the prevalence of the metabolic syndrome and related components by BMI level. The prevalence of the metabolic syndrome and its related components increased across each BMI level.

Among those who are obese, LTPA level is unrelated to the metabolic syndrome. Among the overweight, being inactive increased the odds for the metabolic syndrome by $53 \%[\mathrm{OR}=1.53,95 \% \mathrm{CI}=(1.01,2.32)]$. Among those who are normal weight, LTPA level were not related to the metabolic syndrome (data not shown).

Figures 1 and 2 show the prevalence of the metabolic syndrome and related components by LTPA level in men and women by race, adjusted for age. Overall, those who were inactive had a higher prevalence of the metabolic syndrome and related components compared to those classified as irregularly and regularly active. A step-wise reduction in the prevalence rate of the metabolic syndrome is observed across LTPA level in Caucasian and Hispanic men. This trend is not observed in African American men, Other men, or any of the women's racial groups. In the women, regardless of race, abdominal obesity is the most common component; however, among the men there is no component that is the most prevalent across racial groups.

Table 3 shows the percentage of LTPA levels among US adults enrolled in NHANES III according to race and gender. Regardless of race or gender most adults were irregularly active (56 to 84\%) and less than $15 \%$ were regularly active. Fewer 
Table 1 Descriptive Characteristics for Study Participants (NHANES III, 1988 to 1994)

\begin{tabular}{|c|c|c|c|}
\hline Characteristics & $\begin{array}{c}\text { Men } \\
N=7668\end{array}$ & $\begin{array}{l}\text { Women } \\
N=9013\end{array}$ & $\begin{array}{c}\text { All } \\
N=16,681\end{array}$ \\
\hline Age (y) & $41.9 \pm 0.44$ & $44.6 \pm 0.51$ & $43.1 \pm 0.44$ \\
\hline Weight (kg) & $81.6 \pm 0.38$ & $68.9 \pm 0.37$ & $74.9 \pm 0.29$ \\
\hline Height $(\mathrm{cm})$ & $175.7 \pm 0.20$ & $161.9 \pm 0.17$ & $168.4 \pm 0.20$ \\
\hline Body-mass index $\left(\mathrm{kg} / \mathrm{m}^{2}\right)$ & $26.3 \pm 0.10$ & $26.3 \pm 0.14$ & $26.3 \pm 0.10$ \\
\hline Waist circumference $(\mathrm{cm})$ & $94.4 \pm 0.25$ & $87.6 \pm 0.37$ & $91.1 \pm 0.24$ \\
\hline \multicolumn{4}{|l|}{ Blood pressure (mmHg) } \\
\hline Systolic & $123.8 \pm 0.34$ & $119.0 \pm 0.46$ & $121.3 \pm 0.36$ \\
\hline Diastolic & $76.4 \pm 0.22$ & $71.6 \pm 0.21$ & $73.9 \pm 0.19$ \\
\hline Triglyceride (mg/dL) & $152.5 \pm 2.62$ & $129.7 \pm 2.57$ & $140.5 \pm 2.04$ \\
\hline $\mathrm{HDL}^{-\mathrm{C}^{\mathrm{a}}}(\mathrm{mg} / \mathrm{dL})$ & $45.9 \pm 0.36$ & $55.8 \pm 0.39$ & $50.8 \pm 0.33$ \\
\hline Fasting glucose (mg/dL) & $99.5 \pm 0.52$ & $96.4 \pm 0.57$ & $97.9 \pm 0.40$ \\
\hline \multicolumn{4}{|l|}{ Race $(\%)$} \\
\hline Caucasian & 76 & 76 & 76 \\
\hline African American & 10 & 12 & 11 \\
\hline Hispanic & 6 & 5 & 5 \\
\hline Other & 8 & 8 & 8 \\
\hline \multicolumn{4}{|l|}{ Smoking status (\%) } \\
\hline Current & 32 & 25 & 29 \\
\hline Past & 30 & 19 & 24 \\
\hline Never & 38 & 55 & 47 \\
\hline High cholesterol levels ${ }^{\mathrm{b}}(\%)$ & 33 & 33 & 33 \\
\hline $\begin{array}{l}\text { Taking cholesterol lowering } \\
\text { medication }^{\mathrm{c}}(\%)\end{array}$ & 10 & 13 & 12 \\
\hline Self-reported $\mathrm{HTN}^{\mathrm{d}}(\%)$ & 20 & 24 & 22 \\
\hline Taking HTN medication ${ }^{\mathrm{e}}(\%)$ & 70 & 78 & 75 \\
\hline
\end{tabular}

Note. Values are means and standard errors. ${ }^{\text {H}} \mathrm{HDL}-\mathrm{C}$, high-density-lipoprotein cholesterol; ${ }^{\mathrm{b}}$ self-reported high cholesterol level; ' among those who reported having elevated cholesterol levels; ${ }^{\mathrm{d}} \mathrm{HTN}$, self-reported hypertension status; ${ }^{e}$ among those who reported having HTN.

Table 2 Prevalence of the Metabolic Syndrome by BMI Level

\begin{tabular}{|c|c|c|c|c|}
\hline \multirow[b]{2}{*}{ Variables } & \multicolumn{3}{|c|}{ Body-mass index } & \multirow[b]{2}{*}{$\begin{array}{c}\text { All } \\
N=15,106 \\
\% \text { (SE) }\end{array}$} \\
\hline & $\begin{array}{c}\text { Normal } \\
N=6242 \\
\% \text { (SE) }\end{array}$ & $\begin{array}{l}\text { Overweight } \\
N=5138 \\
\% \text { (SE) }\end{array}$ & $\begin{array}{c}\text { Obese } \\
N=3726 \\
\% \text { (SE) }\end{array}$ & \\
\hline Metabolic syndrome & $4(0.39)$ & $23(0.87)$ & $51(1.51)$ & $20(0.64)$ \\
\hline Abdominal obesity & $6(0.38)$ & $43(1.23)$ & $95(0.77)$ & $36(0.75)$ \\
\hline Elevated fasting glucose & $5(0.41)$ & $11(0.69)$ & $21(1.02)$ & $11(0.42)$ \\
\hline Elevated triglyceride & $16(0.81)$ & $39(1.47)$ & $49(1.46)$ & $30(0.87)$ \\
\hline Low HDL-C & $19(0.98)$ & $34(1.18)$ & $46(1.56)$ & $29(0.88)$ \\
\hline Elevated blood pressure & $21(0.81)$ & $38(1.34)$ & $51(1.58)$ & $33(0.89)$ \\
\hline
\end{tabular}

Note. Values are percentages and standard error of the percentages. 

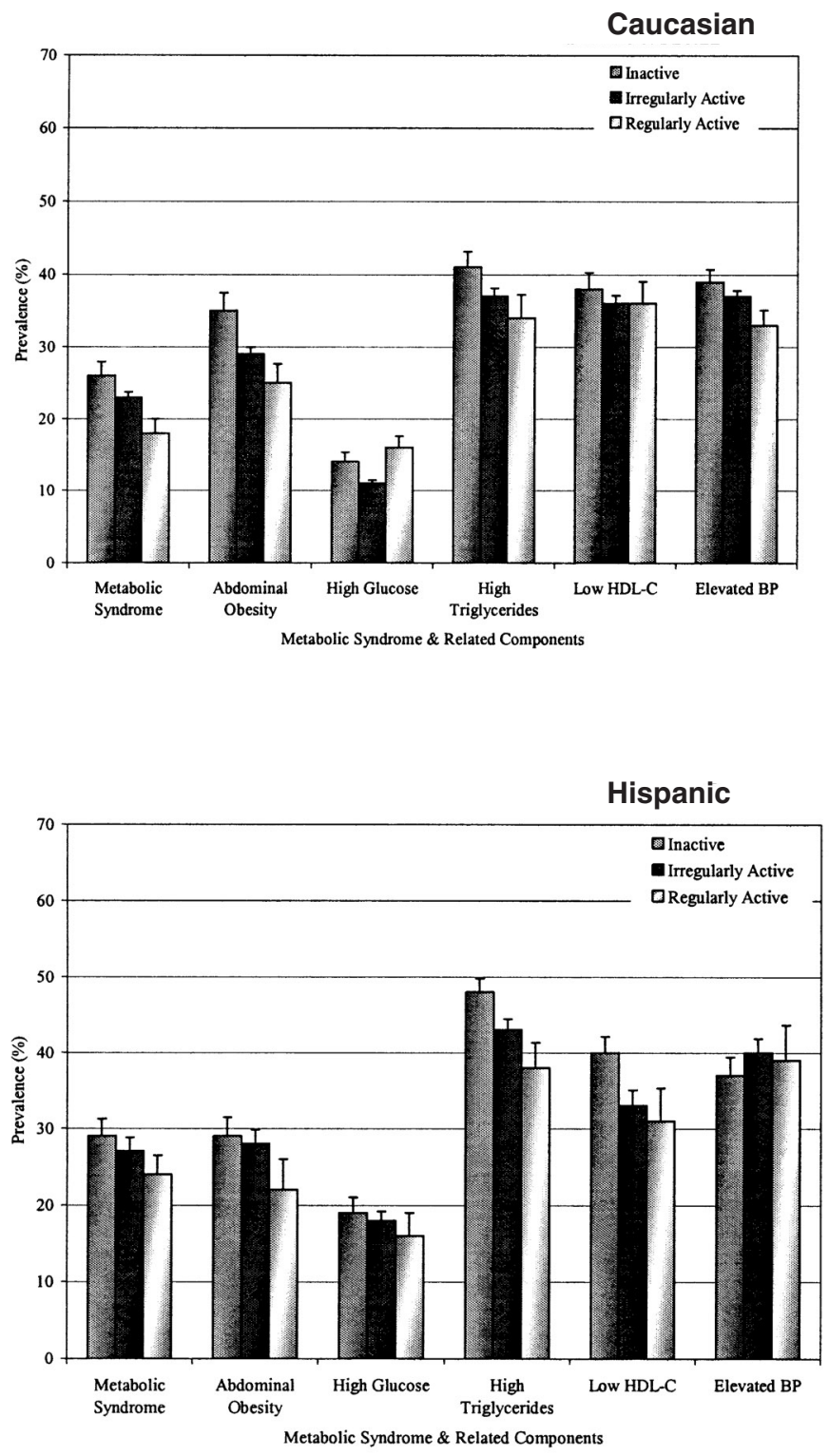

Figure 1 - Prevalence of the Metabolic Syndrome and its Related Components by Leisure-Time Physical Activity Level in Men by Race Adjusted for Age. Note: Caucasian $N=$ 3016, African American $N=2136$, Hispanic $N=2230$, and Other $N=286$. 

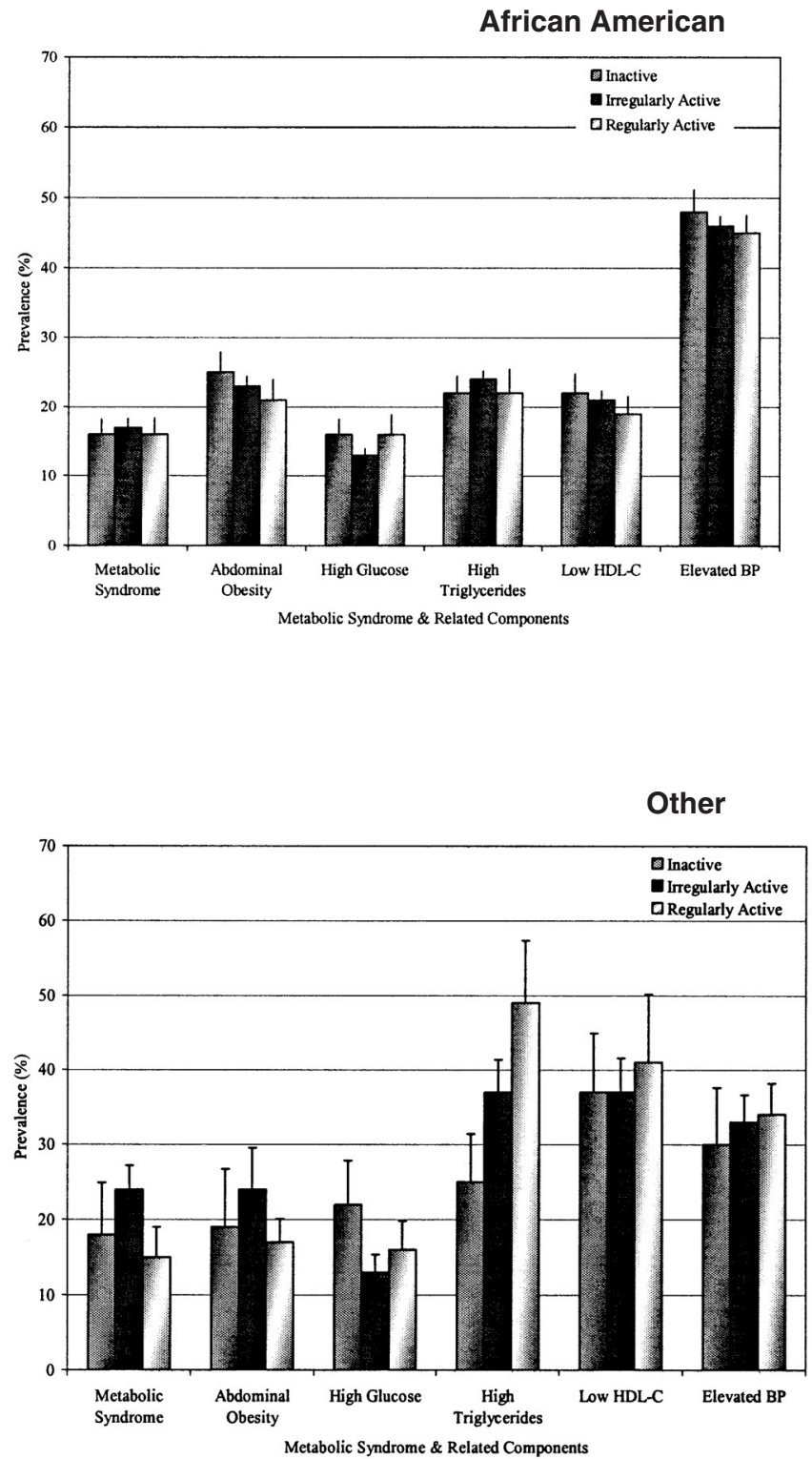

Figure $1-$ (continued) 


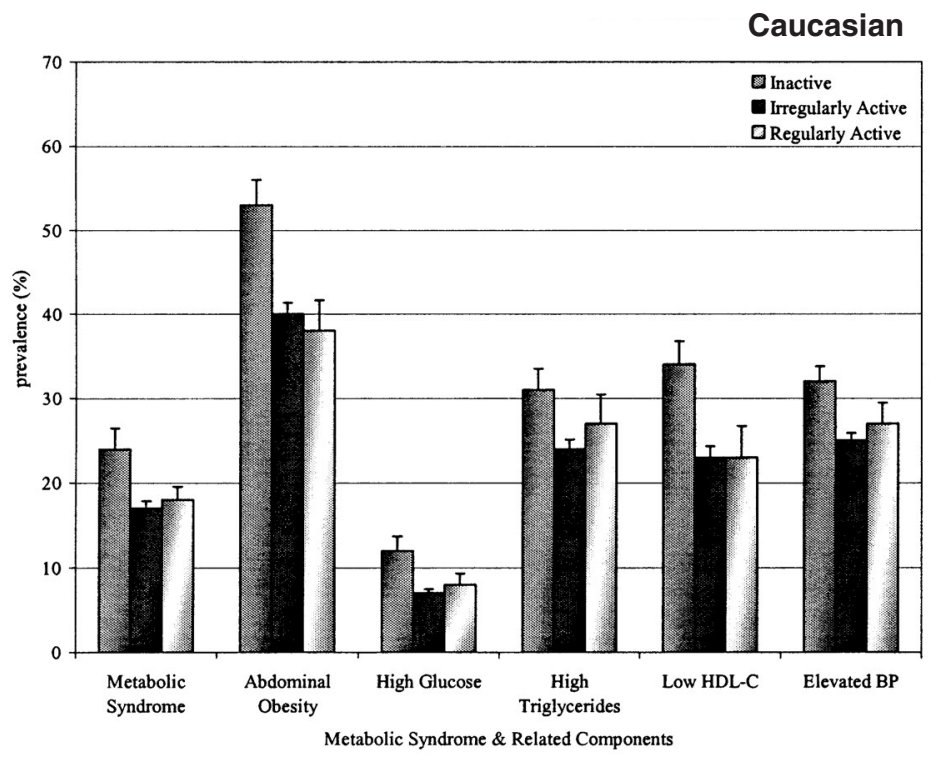

Hispanic

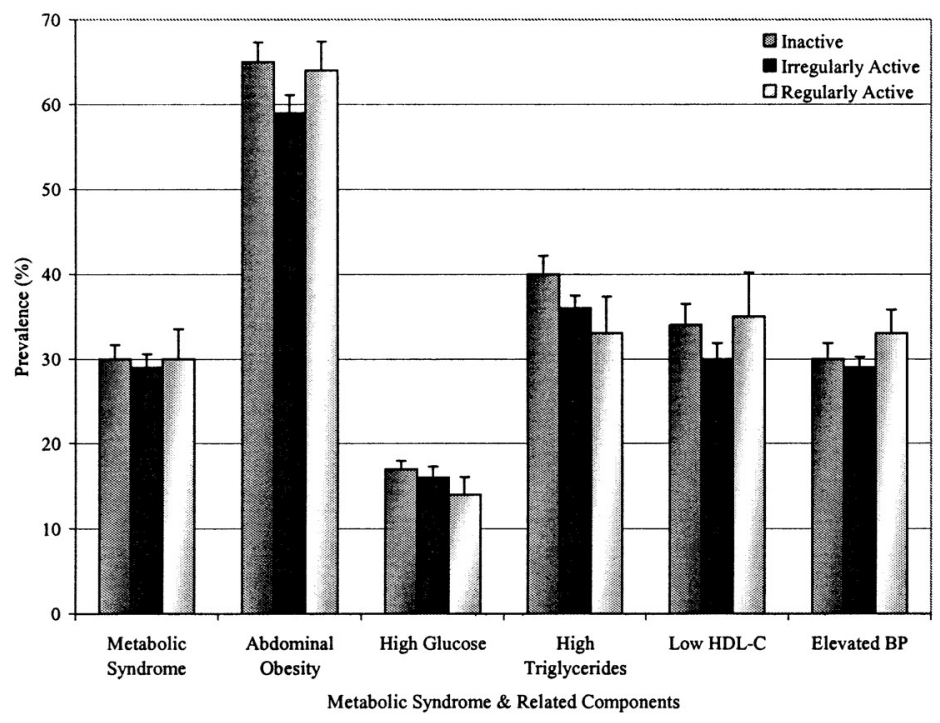

Figure 2 - Prevalence of the Metabolic Syndrome and its Related Components by Leisure-Time Physical Activity Level in Women by Race Adjusted for Age. Note: Caucasian $N=3736$, African American $N=2612$, Hispanic $N=2275$, and Other $N=389$. 

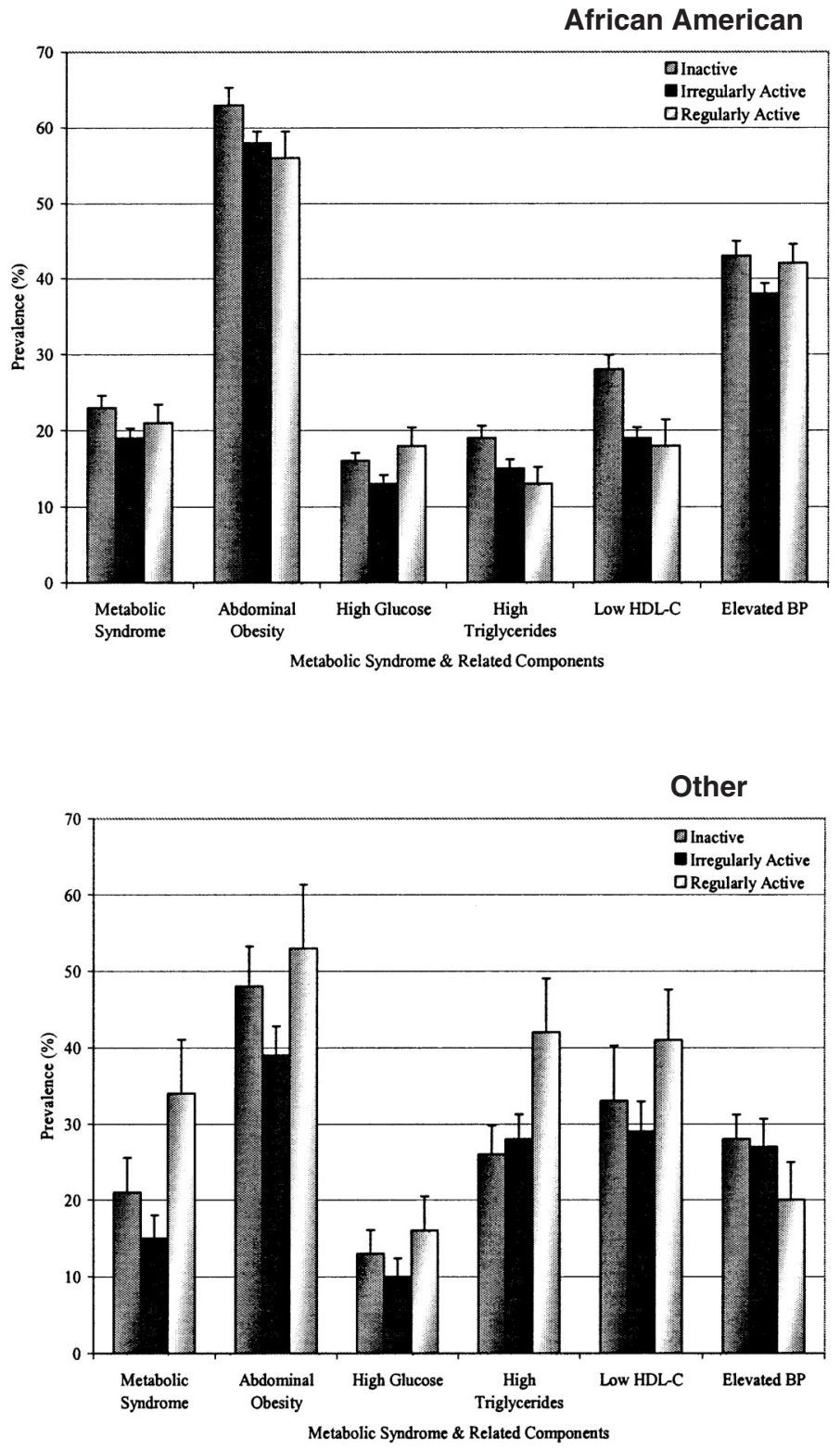

Figure $2-$ (continued) 


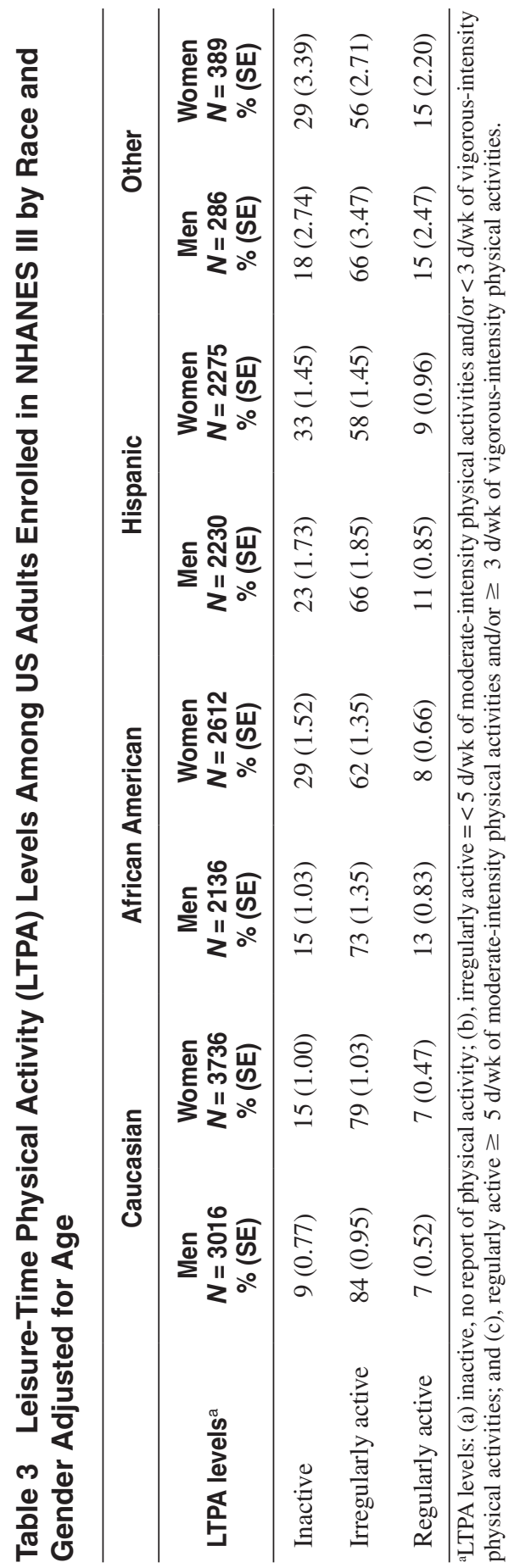


Caucasian men (9\%) and women (15\%) reported inactivity compared to other races (African American: men $=15 \%$, women $=29 \%$; Hispanic: men $=23 \%$, women $=$ $33 \%$; Other: men $=18 \%$, women $=29 \%$ ). Overall, men reported participation in irregular LTPA more and less inactivity than women (irregular: $80 \%$ versus $74 \%$, respectively; inactivity: $11 \%$ versus $18 \%$ ).

Table 4 shows the relationship between the metabolic syndrome, related components of the metabolic syndrome, and LTPA levels in men. Compared to regular participation in LTPA, inactivity and irregular LTPA participation was positively associated with the metabolic syndrome. The odds for developing abdominal obesity were increased for irregular activity $(\mathrm{OR}=1.58,95 \% \mathrm{CI}=1.22,2.04)$ and inactivity $(\mathrm{OR}=1.80,95 \% \mathrm{CI}=1.25,2.61)$ compared to regular participation in LTPA. LTPA was not associated with elevated fasting glucose levels, elevated blood pressure, elevated triglycerides, or low HDL-C.

Table 5 shows the relationship between the metabolic syndrome, related components of the metabolic syndrome, and LTPA levels among women. LTPA was not associated with metabolic syndrome. Inactivity increased the odds for developing abdominal obesity $(\mathrm{OR}=1.62,95 \% \mathrm{CI}=1.22,2.14)$ compared to regular participation in LTPA. The odds of developing elevated fasting glucose levels, elevated blood pressure, and low HDL-C were higher for those in the inactive group, but the results were not statistically significant.

In men, a trend between varying LTPA levels and the metabolic syndrome was observed, where a decrease in LTPA was associated with a greater odds of having the metabolic syndrome $(P=0.004)$. In contrast, a trend was not observed between LTPA levels and the metabolic syndrome in women $(P=0.13)$.

\section{Table 4 The Relationship Between the Metabolic Syndrome and Components of the Metabolic Syndrome and Leisure-Time Physical Activity Levels in Men ${ }^{\mathrm{a}, \mathrm{b}}$}

\begin{tabular}{lccc}
\hline & \multicolumn{3}{c}{ Leisure-time physical activity levels } \\
\cline { 2 - 4 } Variables & $\begin{array}{c}\text { Inactive } \\
\text { OR }(95 \% \text { Cl })^{c}\end{array}$ & $\begin{array}{c}\text { Irregularly active } \\
\text { OR }(95 \% \text { Cl) }\end{array}$ & $\begin{array}{c}\text { Regularly } \\
\text { active OR }\end{array}$ \\
\hline Metabolic syndrome & $1.60(1.11,2.31)^{*}$ & $1.52(1.18,1.98)^{*}$ & 1.0 \\
Abdominal obesity & $1.80(1.25,2.61)^{*}$ & $1.58(1.22,2.04)^{*}$ & 1.0 \\
Elevated fasting glucose & $1.02(0.72,1.46)$ & $0.79(0.58,1.09)$ & 1.0 \\
Elevated triglyceride & $1.14(0.83,1.57)$ & $1.16(0.89,1.52)$ & 1.0 \\
Low HDL-C & $1.08(0.78,1.50)$ & $1.06(0.84,1.34)$ & 1.0 \\
Elevated blood pressure & $1.25(0.90,1.75)$ & $1.18(0.89,1.55)$ & 1.0 \\
\hline
\end{tabular}

aeisure-time physical activity levels: (a) inactive, no report of physical activity; (b) irregularly active, $<5 \mathrm{~d}$ /wk of moderate-intensity physical activities and/or $<3 \mathrm{~d} /$ wk of vigorous-intensity physical activities; and (c) regularly active, $\geq 5 \mathrm{~d} /$ wk of moderate-intensity physical activities and/or $\geq 3 \mathrm{~d} / \mathrm{wk}$ of vigorous-intensity physical activities. ${ }^{\mathrm{b}}$ Adjusting for age, sex, race, and educational attainment. ${ }^{\mathrm{c}} \mathrm{OR}(95 \%$ $\mathrm{CI}$ ), odds ratio (95\% confidence interval). ${ }^{\mathrm{d}} \mathrm{HDL}-\mathrm{C}$, high-density-lipoprotein cholesterol. $* P<0.05$. 


\section{Table 5 The Relationship Between the Metabolic Syndrome and Components of the Metabolic Syndrome and Leisure-Time Physical Activity Levels in Women ${ }^{\mathrm{a}, \mathrm{b}}$}

\begin{tabular}{lccc}
\hline \multirow{2}{*}{ Variables } & \multicolumn{2}{c}{ Leisure-time physical activity levels } \\
\cline { 2 - 4 } & $\begin{array}{c}\text { Inactive } \\
\text { OR }(95 \% \mathbf{C l})^{\mathrm{c}}\end{array}$ & $\begin{array}{c}\text { Irregularly active } \\
\text { OR }(\mathbf{9 5 \%} \mathbf{~ C l})\end{array}$ & $\begin{array}{c}\text { Regularly } \\
\text { active OR }\end{array}$ \\
\hline Metabolic syndrome & $1.18(0.87,1.59)$ & $0.96(0.72,1.27)$ & 1.0 \\
Abdominal obesity & $1.62(1.22,2.14)^{*}$ & $1.21(0.94,1.56)$ & 1.0 \\
Elevated fasting glucose & $1.04(0.73,1.49)$ & $0.79(0.59,1.05)$ & 1.0 \\
Elevated triglyceride & $1.01(0.77,1.32)$ & $0.88(0.67,1.15)$ & 1.0 \\
Low HDL-C & $1.23(0.93,1.63)$ & $0.96(0.74,1.24)$ & 1.0 \\
Elevated blood pressure & $1.31(0.94,1.81)$ & $1.00(0.74,1.34)$ & 1.0 \\
\hline
\end{tabular}

aeisure-time physical activity levels: (a) inactive, no report of physical activity; (b) irregularly active, $<5 \mathrm{~d} /$ wk of moderate-intensity physical activities and/or $<3 \mathrm{~d} /$ wk of vigorous-intensity physical activities; and (c) regularly active, $\geq 5 \mathrm{~d} /$ wk of moderate-intensity physical activities and/or $\geq 3 \mathrm{~d} / \mathrm{wk}$ of vigorous-intensity physical activities. ${ }^{\mathrm{b}}$ Adjusting for age, sex, race, and educational attainment. ${ }^{\mathrm{c}} \mathrm{OR}(95 \%$ $\mathrm{CI}$ ), odds ratio (95\% confidence interval). ${ }^{\mathrm{d}} \mathrm{HDL}-\mathrm{C}$, high-density-lipoprotein cholesterol. $* P<0.05$.

\section{Discussion}

Physical inactivity and irregular activity was associated with the metabolic syndrome in men. In contrast, among the women, inactivity or irregular LTPA was not associated with the metabolic syndrome. When the analysis was run controlling for gender, but not stratified by gender, inactivity was associated with a $45 \%$ increase in the odds of developing the metabolic syndrome $(\mathrm{OR}=1.45,95 \% \mathrm{CI}=1.17$, 1.79). These findings are similar to those reported by Irwin et al. ${ }^{10}$ and Laaksonen et al. ${ }^{11}$ who showed that participation in moderate and moderate-vigorous physical activity was inversely related with the risk for the metabolic syndrome. Park et al. ${ }^{5}$ also used the NHANES III dataset to examine the relationship inactivity had on metabolic syndrome. They also showed that inactivity was related to the metabolic syndrome in men, but not women. Park et al. ${ }^{5}$ developed a score to define inactivity, whereas, in the current study, inactivity was based on the frequency as reported in the CDC-ACSM recommendations. ${ }^{12}$ The current study has taken the results from Park et al. ${ }^{5}$ and expanded on them to determine if a dose-response relationship between LTPA and metabolic syndrome existed and also used LTPA definitions concurrent with present activity guidelines.

In men and women, physical inactivity was related to increased risks for abdominal obesity. In men only, irregular LTPA was related to increased risk for abdominal obesity. The relationship between inactivity and abdominal obesity is similar to what others have reported. ${ }^{18}$ The lack of relationship between other components of the metabolic syndrome is in contrast, however, to others. ${ }^{8,20}$ Wannamethee et al. ${ }^{8}$ showed that participation in moderate-vigorous LTPA reduced the CVD risk factors 
of low HDL-C, high diastolic blood pressure, hyperglycemia, hyperinsulinemia, hyperuriecmia, and $\gamma$-glutamyltransferase. Sternfeld, Sidney, Jacobs, et al. ${ }^{20}$ also reported that decreased physical activity levels over a 7-y period resulted in reduced HDL-C concentrations, and increased body weight, low-density-lipoproteins concentrations, and triglyceride concentrations in the CARDIA study.

In their studies, Irwin et al. ${ }^{10}$ and Laaksonen et al. ${ }^{11}$ reported a dose-response relationship for physical activity, expressed as MET-mins/d and mins/d, respectively, and the metabolic syndrome. A positive dose-response relationship existed in men, but not women. Less LTPA was associated with increased odds of the metabolic syndrome. These results are similar to Laaksonen et al., ${ }^{11}$ who reported a doseresponse relationship among men, but contrary to the findings in women reported by Irwin et al. ${ }^{10}$ Unlike Irwin et al. ${ }^{10}$ and Laaksonen et al.'s ${ }^{11}$ studies, NHANES III did not assess duration, but only frequency and intensity of participation in LTPA. Thus, it is possible that the omission of the duration of physical activity in NHANES III might have limited the ability to detect a stronger dose-response association between physical activity and the metabolic syndrome. Further, measuring the duration of physical activity allows data to be expressed as a volume (e.g., mins/d) and converted to kcal or MET-min of energy expenditure. Wareham, Hennings, Byrne, et al. ${ }^{26}$ expressed their exposure variable as kcals/d and showed that an increase in regular energy expenditure reduced the risk for the metabolic syndrome. Finally, the physical activity questionnaire used assessed leisure-time physical activities and it has been reported that LTPA does not accurately reflect the physical activity habits of women. ${ }^{27}$

Physical activity participation has been associated with many positive effects for components of the metabolic syndrome such as decreased body weight, lower blood pressure, fasting glucose and triglyceride levels, and increased HDL-C concentrations. ${ }^{7,8,20}$ Recently, it was reported that aerobic training is an effective method to treat patients with the metabolic syndrome. ${ }^{21}$ Even though growing evidence suggests that physical activity reduces the risk of the metabolic syndrome, the mechanism(s) for this response is (are) unclear. It is likely that regular physical activity induces reductions in insulin production, ${ }^{22}$ deposition of fat stores,${ }^{23} \mathrm{sym}-$ pathetic nervous system activity, ${ }^{24}$ or a combination of these factors ${ }^{25}$ that might account for the reduction in the metabolic syndrome and its related components. Additional research is needed to understand the mechanism(s) involved in the clustering of the metabolic syndrome components and the impact of physical activity on the combined metabolic effects.

The majority of participants in this study were classified as irregularly active $(77 \%)$. By the nature of how each LTPA category was defined (inactive $=$ no LTPA, irregularly active $=$ completing 1 to $4 \mathrm{~d} /$ wk of moderate-intensity physical activities and/or 1 to $2 \mathrm{~d} /$ wk of vigorous-intensity physical activities, and regularly active $=$ completing 5 to $7 \mathrm{~d} /$ wk of moderate-intensity physical activities and/or 3 to $7 \mathrm{~d} / \mathrm{wk}$ of vigorous-intensity physical activities) the irregular active group was the largest $(n=10,413)$ and most heterogeneous in terms of the frequency of LTPA participation, compared to the inactive group $(n=3222)$ and regularly actives $(n=1497)$. Misclassification of LTPA levels is possible. Some participants in the irregularly active group could have been misclassified and really belonged in the inactive classification. Participation in LTPA only one day in the past month classified one as irregularly active. It is unlikely, however, that those in the inactive group were 
misclassified as irregularly active since classification as inactive required a person to report no LTPA participation during the past month. Given there was no difference between the odds ratios for the irregularly and inactive groups (men: $\mathrm{OR}=1.52$ and 1.60, respectively; women: $\mathrm{OR}=0.96$ and 1.18 , respectively) it is possible that misclassification was present among the irregularly active group. Finally, LTPA misclassification could be due to a person reporting an atypical amount of activity in the past month or the "weekend" warrior concept. ${ }^{28}$

Aspects of the NHANES III study might limit the findings of this study. NHANES III data were collected between the years 1988 to 1994, thus the prevalence of the metabolic syndrome and the relationship between LTPA and the metabolic syndrome might be different than those reported in the current US population. According to BRFSS data, the prevalence of obesity has increased $16.6 \%$ between 1991 and $2000 .{ }^{29}$ Since obesity rates have increased over the past $9 \mathrm{y}$ it is possible that the prevalence of the metabolic syndrome has also increased. Further, NHANES III is a cross-sectional study design and physical activity habits tend to fluctuate throughout a person's lifetime. ${ }^{30}$ Therefore, it is difficult to know the temporal sequence between physical activity levels and the metabolic syndrome. Because LTPA was assessed via self-report for the past month, recall bias was possible especially when reporting the number of days participated in a specific activity during the past month. Further, the physical activity questionnaire used in NHANES III did not assess duration nor has the questionnaire been validated against objective measures of physical activity and energy expenditure. Lastly, the NHANES III physical activity questionnaire was a modified version of the physical activity questionnaire used by the 1985 National Heath Interview Survey and to date no validity or reliability data has been published related to this modified LTPA questionnaire.

\section{Conclusion}

In summary, the results highlight a distinct gender difference between LTPA and the metabolic syndrome. In men, physical inactivity and irregular physical activity increased the odds for developing the metabolic syndrome, but no relationship was observed in women. Regardless of gender, inactivity increased the odds of developing abdominal obesity. Among the men, a trend was observed between LTPA participation and the metabolic syndrome, showing increased odds for the development of the metabolic syndrome with increasing inactivity. A growing body of research suggests that regular physical activity participation reduces the risk for the metabolic syndrome; however, the optimal dose of physical activity to reduce the risk for the metabolic syndrome is unknown. Further, the differential impact physical activity has on gender and the metabolic syndrome needs additional investigation.

\section{References}

1. National Institutes of Health. Third Report of the National Cholesterol Education Program Expert Panel on Detection, Evaluation, and Treatment of High Blood Cholesterol in Adults (Adult Treatment Panel III). NIH Publication. No. 01-3670. 2001. Bethesda, MD: National Institutes of Health, 2001. 
2. Lindblad U, Langer RD, Wingard DL, Thomas RG, Barrett-Connor EL. Metabolic syndrome and ischemic heart disease in elderly men and women. Am J Epidemiol. 2001;153:481-489.

3. Trevisan M, Liu J, Bahsas FB, Menotti A. Syndrome X and mortality: A populationbased study. Am J Epidemiol. 1998;148:958-966.

4. Ford ES, Giles WH, Dietz WH. Prevalence of the metabolic syndrome among US adults: Findings from the Third National Health and Nutrition Examination Survey. JAMA. 2002;287:356-359.

5. Park Y-W, Zhu S, Palaniappan L, Heshka S, Carnethon MR, Heymsield SB. Prevalence and associated risk factor findings in the US population from the third national health and nutrition examination survey, 1988-1994. Arch Intern Med. 2003;163:427-436.

6. Durstine JL, Gandjean PW, Davis PG, Ferguson MA, Alderson NL, DuBose KD. Blood lipid and lipoprotein adaptations to exercise: A quantitative analysis. Sports Med. 2001;31:1033-1062.

7. Irwin ML, Mayer-Davis EJ, Addy CL, Pate RR, Durstine JL, Stolarczky LM, Ainsworth BE. Moderate-intensity physical activity and fasting insulin levels in women: The Cross-Cultural Activity Participation Study. Diabetes Care. 2000;23:449-454.

8. Wannamethee SG, Shaper AG, Alberti KGMM. Physical activity, metabolic factors, and the incidence of coronary heart disease and type 2 diabetes. Arch Intern Med. 2000;160:2108-2116.

9. Brunner EJ, Marmot MG, Nanchacal K, Shipley MJ, Stansfiled SA, Juneja M, et al. Social inequality in coronary disease risk: central obesity and the metabolic syndrome. Evidence from the Whitehall II study. Diabetologia. 1997;40:1341-1349.

10. Irwin ML, Ainsworth BE, Mayer-Davis EJ, Addy CL, Pate RR, Durstine JL. Physical activity and the metabolic syndrome in a tri-ethnic sample of women. Obes Res. 2002;10:1030-1037.

11. Laaksonen DE, Lakka HM, Salonen JT, Niskeanen LK, Rauramaa R, Lakka TA. Low levels of leisure-time physical activity and cardiorespiratory fitness predict development of the metabolic syndrome. Diabetes Care. 2002;25:1612-1618.

12. Alberti KGMM, Zimmet PZ. Definition, diagnosis and classification of diabetes mellitus and its complications Part 1: Diagnosis and classification of diabetes mellitus provisional report of a WHO consultation. Diabetic Medicine. 1998;15:539-553.

13. Pate RR, Pratt M, Blair SN, et al. Physical activity and public health: A recommendation from the Centers for Disease Control and Prevention and the American College of Sports Medicine. JAMA. 1995;273:402-407.

14. Carroll S, Cookie CB, Butterly RJ. Metabolic clustering, physical activity and fitness in nonsmoking, middle-aged men. Med Sci Sports Exerc. 2000;32:2079-2086.

15. National Center of Health Statistics. Plan and operation of the Third National Health and Nutrition Examination 1988-1994: data collection forms. Hyattsville, MD: National Center for Health Statistics, 1994. (Vital and health statistics, series 1: programs and collection procedures, no. 32) (DHHS publication no. (PHS) 94-1308) (GPO no. 017022-01260-0).

16. Ainsworth BE, Haskell WL, Leon AS, Jacobs DR Jr, Montoye HJ, Sallis JF, et al. Compendium of physical activities: classification of energy costs of human physical activities. Med Sci Sports Exerc. 1993;25:71-80.

17. Crespo CJ, Keteyian SJ, Heath GW, Sempost CT. Leisure-time physical activity among US adults: Results from the Third National Health and Nutrition Examination Survey. Arch Intern Med. 1996;156:93-98.

18. National Institutes of Health. Clinical guidelines on the identification, evaluation, and treatment of overweight and obesity in adults. Obes Res. 1998;6:51S-109S.

19. National Heart Lung, and Blood Institute, Lipid Research Clinics Program. Manual of laboratory operations: Lipid and lipoprotein analyses. $2 \mathrm{~d}$ ed. Washington: US Govt Printing Office, 1982. 
20. Sternfeld B, Sidney S, Jacobs DR Jr, Sadler MC, Haskell WL, Schreiner PJ. Seven-year changes in physical fitness, physical activity and lipid profile in the CARDIA study. Ann Epidemiol. 1999;9:25-33.

21. Wareham NJ, Hemmings SJ, Byrne CD, Hales CN, Prentice AM, Day NE. A quantitative analysis of the relationship between habitual physical energy expenditure, fitness and the metabolic syndrome. Br J Nutr. 1998;80:235-241.

22. Mâsse LC, Ainsworth BE, Tortolero S, Levin S, Fulton JE, Henderson KA, Mayo K. Measuring physical activity in midlife, older and minority women: Issues from an expert panel. J Women's Health. 1998;7:57-67.

23. Katzmarky PT, Leon AS, Wilmore JH, Skinner JS, Rao DC, Rankinen T, Bouchard C. Targeting the metabolic syndrome with exercise: evidence from the HERITAGE Family Study. Med Sci Sports Exerc. 2003;35:1703-1709.

24. Wannamethee SG, Sharper AG, Durrington PN, Perry IJ. Hypertension, serum insulin, obesity and the metabolic syndrome. J Hum Hypertens. 1998;12:735-741.

25. Maison P, Byrne CD, Hales CN, Day NE, Wareham NJ. Do different dimensions of the metabolic syndrome change together over time? Evidence supporting obesity as the central feature. Diabetes Care. 2001;24:1758-1763.

26. Bjorntorp P, Holm G, Rosmond R. Hypothalamic arousal, insulin resistance and type 2 diabetes mellitus. Diabet Med. 1999;16:373-383.

27. Anderson PJ, Critchley JA, Chan JC, Cockram CS, Lee ZSK, Thomas GN, et al. Factor analysis of the metabolic syndrome: Obesity vs insulin resistance as the central abnormality. Int J Obes Relat Metab Disord. 2001;25:1782-1788.

28. Lee IM, Sesso HD, Oguma Y, Paffenbarger RS Jr. The "weekend warrior" and risk of mortality. Am J Epidemiol. 2004;160:636-641.

29. Mokdad AH, Bowman BA, Ford ES, Vinicor F, Marks JS, Koplan JP. The continuing epidemics of obesity and diabetes in the United States. JAMA. 2001;286:1195-1200.

30. Norman A, Bellocco R, Viada F, Wolk A. Age and temporal trends of total physical activity in Swedish men. Med Sci Sports Exerc. 2003;35:617-622. 